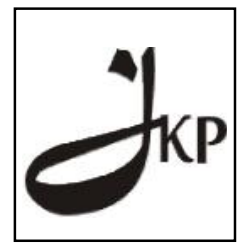

Jurnal Konseling dan Pendidikan

ISSN Cetak: 2337-6740 - ISSN Online: 2337-6880

http://jurnal.konselingindonesia.com

Volume 1 Nomor 2, Juni 2013, HIm 143-150

Info Artikel:

Diterima 15/06/2013

Direvisi 26/06/2013

Dipublikasikan 30/06/2013

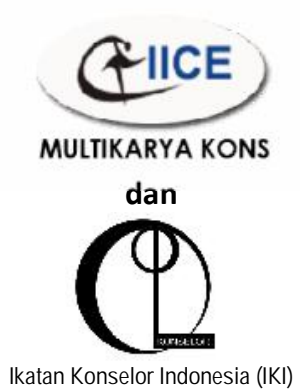

\title{
Kondisi Stres Akademik Siswa SMA Negeri di Kota Padang
}

\author{
Taufik $^{1}$ Ifdil $^{2} \&$ Zadrian $_{\text {Ardi }}{ }^{3}$
}

${ }^{123}$ Fakultas Ilmu Pendidikan, Universitas Negeri Padang

\begin{abstract}
This research conduct base from increasing the National Examination standards from recent years, and overload student's learning activity in Senior High Scholl (SMA). These conditions as triggers stress students, from a long time, its influence on their learning. Based that, the research is to identify level of student academic stress, and differences base gender, and school location. This research use Cluster Random Sampling. Samples are grouped into 3 (three), that's school is located in downtown, midtown and the Suburbs. Research findings show that there are 15\% of student's stress academic at low levels of, $71,8 \%$ experiencing stress academic at medium level, and $13.2 \%$ of students experiencing stress academic at high level. There was no significant difference between the academic stress Student SMAN in Padang by location and gender. These research findings can then be an important basic need for guidance and counseling services in order to decrease the level of stress of academic students in Padang city, so that they can learn by making every effort that is optimal.
\end{abstract}

Keyword: Stres, stress akademik, konseling, SMA

Copyright () 2013 IICE - Multikarya Kons (Padang - Indonesia) dan IKI - Ikatan Konselor Indonesia - All Rights Reserved Indonesian Institute for Counseling and Education (IICE) Multikarya Kons

\section{PENDAHULUAN}

Masa remaja merupakan masa storm and stress, di mana merupakan masa yang bergolak dan berisi konflik serta perubahan suasana hati. ( Payne, M. A. 2012; Arnett, J. J. 2006), yang dapat menyebabkan depresi (Byrne \& Mazanov, 2007; Deardorff \& Sandler, 2003; Lazaratou \& Soldatos , 2010). Kondisi ini disebabkan karena banyaknya goncangan-goncangan dan perubahan yang cukup radikal dari masa sebelumnya (Santrock, 2003; Hurlock, 1994).

Perubahan tuntutan belajar dari masa sebelumnya juga menyebabkan munculnya gejala stress. Kondisi ini antara lain disebabkan oleh tuntutan yang tinggi terhadap prestasi siswa. Dari tahun ke tahun Kementerrian Pendidikan dan Kebudayaan menetapkan standar kelulusan yang selalu meningkat. Di samping itu pemerintah

\footnotetext{
* Telp atau Alamat Email Koresponden :

${ }^{1}$ E-mail address: taufik@konselor.org
} 
daerah kabupaten dan kota juga menuntutdan kadangkal menekan pihak sekolah agar mencapai prestasi yang tinggi serta tingkat kelulusan siswa yang harus mendekati $100 \%$. Di pihak lain beban belajar siswa di SMA juga ditrasa banyak. Tuntutan yang tinggi itu seringkali menjadi pemicu munculnya stres pada peserta didik, khususnya pada mereka yang tidak memiliki kesiapan dan kedisiplinan dalam belajar. Menurut Baldwin (dalam Desmita, 2009) dalam menghadapi beban pelajaran yang dirasa cukup berat di sekolah akan dapat menimbulkan stress pada remaja, terutama bagi remaja high school, mengingat pada masa ini remaja pada umumnya mengalami tekanan dari pihak sekolah dan kadangkala dari orang tua untuk memperoleh nilai yang tinggi agar dapat melanjutkan pendidikan ke perguruan tinggi favorit. Lebih lanjut Rainham (dalam Desmita, 2009) menyatakan bahwa pada masa-masa sekolah menengah disatu sisi merupakan kesempatan untuk mendapatkan pengalaman yang sangat berharga bagi remaja, tetapi disisi lain mereka dihadapkan dengan banyaknya tuntutan dan perubahan yang cepat yang pada kahirnya dapat membuat mereka mengalami masa-masa yang penuh dengan stress.

Sebagian besar sumber stress siswa berasal dari masalah akademik (Elias, 2011). Stres di bidang akademik pada anak muncul ketika harapan untuk meraih prestasi akademik meningkat, baik dari orang tua, guru ataupun teman sebaya. Harapan tersebut seringkali tidak sesuai dengan kemampuan yang mereka miliki (Shahmohammadi, 2011).

Di kalangan remaja Indonesia banyak ditemukan fenomena ketidakmampuan siswa mengelola stress. Akibatnya akan berbuntut pada hal-hal tragis seperi melarikan diri dan bunuh diri misalnya, seorang siswa shock dan bunuh diri karena tidak lulus UN (Kompasiana, 2011), Karena malu dengan nilai raport rendah, seorang siswi di bekasi menggantungkan diri (Ehan, 2011), Peristiwa di Medan seorang gadis bunuh diri dengan loncat dari lantai 4 sebuah plaza karena tidak naik kelas (Global Medan 2010). Dalam kurun waktu lima bulan terakhir sampai November 2011, di Kabupaten Banyumas terdapat 12 kasus bunuh diri dengan berbagai motif. Dari 12 kasus tersebut, lima kasus terbaru dilakukan oleh pelaku yang masih berusia remaja (Suara Merdeka, 2011). Angka kasus bunuh diri pada kalangan anak hingga remaja di Indonesia termasuk tinggi di Asia. Menurut Organisasi Kesehatan Dunia WHO, pada 2005 tercatat 50 ribu penduduk Indonesia bunuh diri setiap tahun. Dari kejadian kasus bunuh diri tersebut, ternyata kasus yang paling tinggi terjadi pada rentang usia remaja hingga dewasa muda, yakni 15-24 tahun (Kompasiana.b, 2011).

Banyaknya kasus-kasus yang terjadi dan semakin banyak stresor yang timbul, semakin meningkat pula tingkat stres pada remaja. Oleh karenanya penelitian ini dilakukan merupakan langkah awal untuk mendeskripsi tingkat stress yang terjadi di SMA Negeri di Kota Padang. Sehingga dapat menjadi data awal untuk menentukan langkah lanjut bagi terentasnya permasalahan stress di kalangan siswa

\section{TUJUAN PENELITIAN}

Penelitian dilakukan untuk mengungkapkan tingkat stress akademik siswa di SMA Negeri Kota Padang, penetilian ini lebih lanjut akan mengidentifikasi tingkat perbedaan stress akademik berdasarkan jenis kelamin dan lokasi sekolah.

\section{METODOLOGI}

Penelitian ini adalah penelitian kuantitatif deskriptif (Marguerite et. Al., 2006: Kultar Singh, 2007) dengan populasi siswa SMA Negeri di Kota Padang yang ada di Kota Padang. Sample diambil dengan menggunakan teknik Cluster Random Sampling sampling yang dibagi menjadi 3 (tiga) kelompok yaitu sekolah di pusat kota, 
tengah kota dan pinggiran kota dengan total sampel 319 siswa. Intrumen digunakan Skala Stres Akademik (SSA). Data dianalisis dengan menggunakan statistik deskriptif dan untuk analisis perbedaan tingkat stress akademik berdasarkan jenis kelamin dan lokasi sekolah dilakukan ujibeda dengan menggunakan ANOVA dan t-test menggunakan SPSS Ver. 17.

\section{HASIL PENELITIAN}

\section{Tingkat Stres Siswa SMA Negeri Kota Padang}

Setelah analisis statistik dengan, maka diperoleh data seperti pada Tabel 1 sebagai berikut:

TABLE 1

Deskripsi Stres Akademik Siswa

\begin{tabular}{|c|c|c|c|c|c|}
\hline \multicolumn{6}{|c|}{ Klasifikasi } \\
\hline & & Frequency & Percent & Valid Percent & $\begin{array}{l}\text { Cumulative } \\
\text { Percent }\end{array}$ \\
\hline \multirow[t]{4}{*}{ Valid } & Rendah & 48 & 15.0 & 15.0 & 15.0 \\
\hline & Sedang & 229 & 71.8 & 71.8 & 86.8 \\
\hline & Tinggi & 42 & 13.2 & 13.2 & 100.0 \\
\hline & Total & 319 & 100.0 & 100.0 & \\
\hline
\end{tabular}

Dari tabel tersebut dapat digambarkan bahwa $15 \%$ siswa SMA Negeri kota Padang berada pada tingkat stres akademik rendah, 71,8 \% siswa SMA Negeri kota Padang berada pada tingkat stres akademik sedang, 13,2 $\%$ siswa SMA Negeri kota Padang berada pada tingkat stres akademik tinggi. Dapat disimpulkan bahwa siswa SMA Negeri kota Padang yang mempunyai prosentase paling banyak adalah siswa yang berada dalam kategori tingkat stres akademik sedang $(71,8 \%)$.

\section{Tingkat stres akademikk siswa SMA Negeri di Kota Padang berdasarkan jenis kelamin}

Setelah analisis statistik maka diperoleh data sebagai berikut:

Table 2

Perbedaan Stress Berdasarkan Jenis Kelamin

\section{Group Statistics}

\begin{tabular}{|c|c|c|c|c|c|}
\hline & JK & $\mathrm{N}$ & Mean & Std. Deviation & Std. Error Mean \\
\hline \multirow{2}{*}{ Total } & Perempuan & 209 & 92.80 & 9.359 & .647 \\
\hline & Laki-Laki & 110 & 93.73 & 10.516 & 1.003 \\
\hline
\end{tabular}

Berdasarkan data di atas dapat disimpulkan bahwa rata-rata tingkat stres siswa perempuan adalah 92,80 ( kategori sedang), sedangkan siswa laki-laki adalah 93,73 (kategori sedang). 
Jurnal Konseling dan Pendidikan

http://jurnal.konselingindonesia.com
Vol. 1 No. 2, Juni 2013. hlm. $x x-x x$

\section{Perbedaan tingkat stres akademik siswa SMA Negeri di Kota Padang berdasarkan jenis kelamin}

Setelah analisis statistik dengan, maka diperoleh data sebagai berikut

Table 3

t-Test Stress Akademik Berdasarkan Jenis Kelamin

Independent Samples Test

\begin{tabular}{|c|c|c|c|c|c|c|c|c|c|c|}
\hline \multirow{5}{*}{ Total } & & \multicolumn{2}{|c|}{$\begin{array}{l}\text { Levene's Test } \\
\text { for Equality of } \\
\text { Variances }\end{array}$} & \multicolumn{7}{|c|}{ t-test for Equality of Means } \\
\hline & & \multirow[t]{2}{*}{$\mathrm{F}$} & \multirow[t]{2}{*}{ Sig. } & \multirow[t]{2}{*}{$\mathrm{t}$} & $d f$ & \multirow[t]{2}{*}{$\begin{array}{l}\text { Sig. } \\
\text { tailed) }\end{array}$} & $\begin{array}{l}\text { Mean } \\
\text { Difference }\end{array}$ & $\begin{array}{l}\text { Std. Error } \\
\text { Differenc } \\
\text { e }\end{array}$ & \multicolumn{2}{|c|}{$\begin{array}{l}95 \% \text { Confidence } \\
\text { Interval of the } \\
\text { Difference }\end{array}$} \\
\hline & & & & & & & & & Lower & $\begin{array}{l}\text { Uppe } \\
r\end{array}$ \\
\hline & $\begin{array}{l}\text { Equal } \\
\text { variances } \\
\text { assumed }\end{array}$ & 2.407 & .122 & $\begin{array}{l}- \\
.80 \\
2 \\
\end{array}$ & 317 & .423 & -.923 & 1.151 & -3.188 & 1.341 \\
\hline & $\begin{array}{l}\text { Equal } \\
\text { variances } \\
\text { not assumed }\end{array}$ & & & $\begin{array}{l}- \\
.77 \\
4\end{array}$ & $\begin{array}{l}200.54 \\
8\end{array}$ & .440 & -.923 & 1.193 & -3.277 & 1.430 \\
\hline
\end{tabular}

Tabel diatas menunjukkan bahwa nilai $\mathrm{F}$ untuk jenis kelamin dengan equal variance assumed adalah 2,407dengan signifikansi 0, 122. Karena probabilitas $>0,05$ sehingga menunjukkan bahwa kedua varians dari populasi adalah sama. Oleh karena itu, nilai t-test yang akan dipakai berdasar kepada nilai equal variances assumed.

Berdasarkan nilai t-test yang diperoleh terlihat bahwa t hitung adalah -0,802 dengan signifikansi 0 , 423. Oleh karena signifikansi 0, $423>0,05$ maka diperoleh kesimpulan bahwa tidak terdapat perbedaan yang signifikan antara tingkat stres akademik siswa laki-laki dan siswa perempuan, dengan kata lain tidak terdapat perbedaan yang signifikan tingkat stres akademik siswa dari jenis kelamin.

\section{Perbedaan tingkat Stress akademik siswa SMA Negeri di Kota Padang berdasarkan lokasi sekolah}

Setelah analisis statistik dengan menggunakan ANOVA dilakukan, maka diperoleh Nilai Mean menunjukkan tidak ada perbedaan yang besar tingkat stres akademik siswa antar masing- masing daerah yaitu rata-rata siswa yang berada di lokasi sekolah pinggiran kota berada dalam kategori tingkat stres akademik sedang (92.80), siswa yang berada di lokasi tengah kota berada dalam kategori tingkat stres akademik sedang (91.97), demikian juga siswa yang berada di lokasi sekolah pusat kota juga berada dalam kategori sedang (94.32). 
Table 4

Tes Homogenitas Varian

Test of Homogeneity of Variances

\begin{tabular}{|l|l|l|l|}
\hline Total & & & \\
Levene Statistic & $\mathrm{df1}$ & $\mathrm{df2}$ & Sig. \\
\hline 4.412 & 2 & 316 & .013
\end{tabular}

ANOVA

\begin{tabular}{|c|c|c|c|c|c|}
\hline \multicolumn{6}{|l|}{ Total } \\
\hline & Sum of Squares & df & Mean Square & $\mathrm{F}$ & Sig. \\
\hline Between Groups & 270.963 & 2 & 135.482 & 1.424 & .242 \\
\hline Within Groups & 30061.269 & 316 & 95.131 & & \\
\hline Total & 30332.232 & 318 & & & \\
\hline
\end{tabular}

Sedangkan dari data di atas, diketahui bahwa nilai F adalah 1,424 dengan signifikansi 0, 242. Oleh karena $t_{\text {hitung }}>t_{\text {tabel }}(0,242 .>0,05)$ maka dapat ditarik kesimpulan bahwa tidak terdapat perbedaan yang signifikan antara tingkat stres akademik siswa SMA Kota Padang yang berada pada sekolah yang berlokasi di pusat kota, tengah kota dan pinggiran kota atau tingkat stres akademik siswa SMA di semua daerah kota padang rata-rata sama yaitu berada pada kategori sedang $(93,12)$ Artinya tidak ada perbedaan tingkat stres akademik siswa berdasarkan daerah belajar.

\section{PEMBAHASAN}

\section{Tingkat Stres Akademik Siswa SMA Negeri Kota Padang}

Berdasarkan hasil penelitian, tingkat stres akademik siswa SMA Negeri kota Padang tergolong berada dalam kategori tingkat stres akademik sedang yaitu sebesar 71,8 \%. Sementara itu 13,2\% siswa SMA Negeri kota Padang berada pada tingkat stres akademik tinggi dan $15 \%$ siswa SMA Negeri kota Padang berada pada tingkat stres akademik rendah. Hal ini berarti bahwa kondisi siswa SMA Negeri Kota padang merasakan kondisi stres akademik, akan tetapi mereka masih dapat mengontrol/mengelolanya.

Siswa SMA Negeri Kota Padang masih dapat mengontrol situasi atau kondisi penyebab munculnya stres yang berkaitan dengan berbagai tuntutan akademis. Menurut Lazarus (1984), berpendapat bahwa sesuatu yang menimbulkan stres tergantung pada bagaimana individu menilai dan menginterpretasikan suatu kejadian secara kognitif. Penilaian kognitif (cognitive appraisal) yang digunakan Lazarus menggambarkan interpretasi individu terhadap kejadian-kejadian dalam hidup mereka sebagai sesuatu yang berbahaya, mengancam, atau menantang dan keyakinan mereka apakah mereka memiliki kemampuan untuk menghadapi suatu kejadian dengan efektif.

Kemampuan siswa mengontrol situasi atau kondisi penyebab munculnya stres yang berkaitan dengan berbagai tuntutan akademis menurut pandangan Lazarus (dalam Santrock, 2003) melalui dua langkah:

1) Penilaian primer (primary appraisal), mengartikan apakah suatu kejadian mengandung bahaya atau menyebabkan kehilangan, menimbulkan suatu ancaman akan bahaya di masa yang akan datang atau tantangan yang harus dihadapi.

2) Penilaian sekunder (secondary appraisal), mengevaluasi potensi atau kemampuan dan menentukan seberapa efektif potensi atau kemampuan yang dapat digunakan untuk menghadapi suatu kejadian. 
Meskipun secara umum kondisi tingkat stres akademik siswa SMA Negeri kota Padang berada pada kategori sedang, akan tetapi banyak juga diantara mereka yang berada dalam kategori tingkat stres akademik tinggi yaitu sebesar 13,2 \%. Hal ini berarti bahwa siswa SMA Negeri kota Padang tidak luput dari kondisi stres akibat berbagai tuntutan akademik.

Selain hal tersebut, dalam hasil penelitian $15 \%$ siswa SMA Negeri kota Padang berada pada tingkat stres akademik rendah. Dalam hal ini membuktikan bahwa stress akademik tidak sepenuhnya bermakna negatif melainkan dapat bermakna positif dalam artian dapat sebagai tantangan untuk mengatasinya. Stress ini tidak membahayakan, malah sebaliknya diperlukan untuk meningkatkan kualitas diri dan prestasi belajar (Desmita, 2009). Seseorang yang menilai stress sebagai tantangan (Challenge) akan memiliki semangat yang tinggi, karena merasa tertantang berarti merasa positif terhadap tuntutan yang dihadapi (Cooper, 2004).

Dalam upaya mereduksi stres menurut Lazarus dan Folkman (Cooper, 2004; Kavanagh, 2005; Aldwin, 2007, Larkin, Kevin T. 2005) ada dua strategi yang dilakukan seseorang dalam melakukan coping, yaitu:

a. Problem-focused coping adalah usaha mengatasi stres dengan cara mengatur atau mengubah masalah yang dihadapi dan lingkungan sekitar yang menjadi penyebab tekanan.

b. Emotion-focused coping adalah usaha mengatasi stres dengan cara mengatur respon emosional dalam rangka menyesuaikan diri dengan dampak yang akan ditimbulkan oleh suatu kondisi atau situasi yang dianggap penuh tekanan.

Individu cenderung menggunakan problem focused coping untuk kondisi yang dapat dikontrolnya dan menggunakan Emotion focused coping dalam menghadapi masalah-masalah yang sulit dikontrol, namun terkadang individu juga menggunakan strategi coping tersebut secara bersamaan, meski tidak semua strategi coping juga dapat digunakan individu. Hal inilah yang dapat membuat seseorang terhindar atau mengalami stres akademik rendah.

\section{Perbedaan tingkat stres akademik siswa SMA Negeri di Kota Padang berdasarkan jenis kelamin}

Berdasarkan hasil penelitian menunjukkan tidak terdapat perbedaan yang signifikan antara tingkat stres akademik siswa laki-laki dan siswa perempuan. Nilai t-test yang diperoleh terlihat bahwa t hitung adalah $-0,802$ dengan signifikansi 0,423 . Oleh karena signifikansi $0,423>0,05$ maka diperoleh kesimpulan bahwa tidak terdapat perbedaan yang signifikan antara tingkat stres akademik siswa laki-laki dan siswa perempuan, dengan kata lain tidak terdapat perbedaan yang signifikan tingkat stres akademik siswa dari jenis kelamin. Hal ini berarti kondisi tingkat stres siswa baik siswa perempuan dan siswa laki-laki berada dalam kategori hampir sama atau perbedaannya tidak signifikan, meskipun secara gambaran umum nilai rata-rata keduanya berbeda rata-rata tingkat stres siswa perempuan adalah 92,80 sedangkan siswa laki-laki adalah 93,73.

Hasil penelitian ini mendukung penelitian Leadbeater (1999) yang menunjukkan bahwa reaktivitas stres tidak berbeda antara anak perempuan dan anak laki-laki. Namun hasil penelitian ini juga bertolak belakang dengan hasil penelitian Liu (2011) dalam penelitiannya melalui analisis regresi multinomial mengungkapkan bahwa siswi perempuan memiliki tingkat orientasi prestasi lebih tinggi di sekolah sehingga menyebabkan gejala stress yang lebih sering. Beberapa studi menunjukkan bahwa perempuan lebih menanggapi terhadap stresor daripada anak laki-laki (Ge et all, 1994; Hankin, et al, 2007; MacKinnon, et all, 2002 ).

Menurut Lazarus (1984) pria cenderung menggunakan problem focused coping karena pria menggunakan rasio atau logika sehingga mereka memilih untuk langsung menyelesaikan masalah yang dihadapi atau langsung mengahdapi sumber stres. Sedangkan wanita dikatakan lebih cenderung menggunakan emotion focused coping 
karena mereka lebih emosional sehingga cenderung untuk mengatur emosi emosi mereka dalam mengahadapi sumber stres.

\section{Perbedaan tingkat stres akademik siswa SMA Negeri di Kota Padang berdasarkan lokasi sekolah.}

Berdasarkan hasil analisis diperoleh terlihat bahwa t hitung adalah 1,424 dengan signifikansi 0, 242. Oleh karena signifikansi 0,242 >0,05 maka diperoleh kesimpulan bahwa tidak terdapat perbedaan yang signifikan antara tingkat stres akademik siswa yang berada pada sekolah yang berlokasi di pusat kota, tengah kota dan pinggiran kota, dengan kata lain tidak ada perbedaan tingkat stres akademik siswa berdasarkan daerah belajar. Meskipun secara gambaran umum nilai rata-rata tingkat stres akademik di ketiga daerah sekolah tersebut berbeda yaitu siswa yang berada di lokasi sekolah pusat kota dalam kategori sedang lebih tinggi (94.32) dari pada siswa yang berada di lokasi sekolah pinggiran kota yaitu rata-rata 92.80 dan rata-rata siswa yang berada di lokasi tengah kota 91.97.

\section{KESIMPULAN DAN REKOMENDASI}

Penelitian ini mengindentifikasi tingkat stress akademik yang terjadi pada siswa SMA Negeri di Kota Padang mayoritas pada sedang dan tinggi sehingga hasil penelitian ini merekomendasikan perlunya layanan bimbingan dan konseling untuk menurunkan level stress yang dialami siswa dan bahkan pelayanan hingga menghilangkan stress academik yang dialami siswa. Siswa memperoleh bantuan untuk mengelola stress yang dialaminya, sehingga fungsinya sebagai siswa dapat di optimalkan

\section{KETERBATASAN PENELITIAN}

Penelitian ini hanya melibatkan siswa SMA Negeri di Padang, maka ini hasil penelitian tidak dapat digeneralisasi untuk semua siswa yang berada di Padang. Oleh karena itu, penelitian ini harus dilanjutkan di semua sekolah di Padang termasuk sekolah swasta yang ada di Kota Padang.

\section{DAFTAR RUJUKAN}

Arnett, J. J. (2006). G. Stanley Hall's Adolescence: Brilliance and nonsense. History of Psychology, 9, 186-197.

Byrne, D. G., Davenport, S. C., \& Mazanov, J. (2007). Profiles of adolescent stress: The development of the adolescent stress questionnaire (ASQ). Journal of Adolescence, 30, 393-416.

Cooper, Cary. (2004). A brief history of stress. India : Blackwell Publishing.

Deardorff, J., Gonzales, N. A., \& Sandler, I. N. (2003). Control beliefs as a mediator of the relationship between stress and depressive symptoms among inner city adolescents. Journal of Abnormal Child Psychology, $31,205-217$.

Desmita. (2005). Hubungan Antara Stress Sekolah Dengan Derajat Stress dan Strategi Penanggulangan Pada Siswa MAN Model Bukittinggi. Tesis. Bandung:Universitas Padjajaran

Ehan. (2011). Bullying Dalam Pendidikan. Bandung : Universitas Pendidikan Indonesia

Elias. (2011). Stress and academic achievement students. Journal Of Social And Behavioral Sciences. 29, 646655.

Ge, X., Lorenz, F. O., Conger, R. D., Elder, G. H., \& Simons, R. L. (1994). Trajectories of stressful life events and depressive symptoms during adolescence. Developmental Psychology, 30, 467-483.

Global Medan. (2010). Stres Tidak Naik Kelas, Loncat dari Lantai 4 Plaza Medan Fair (Online) (http://m.cititalk.com/read.php?nid=1078 di akses 20 Maret 2013)

Hankin \& Abramson. (1998). Development of depression from preadolescence to young adulthood: Emerging gender differences in a 10-year longitudinal study. Journal of Abnormal Psychology. 107, 128-140 . 
Hurlock, B. E. (1994). Psikologi Perkembangan. Alih bahasa: Sijabat, M.R Jakarta: Erlangga.

Kompasiana, (2011). Ujian Nasional antara prestasi atau sekedar lulus. (online) (www.kompasiana.com diakses 6 Maret 2012).

Kompasiana.b. 2011. Kasus Bunuh Diri Kembali Marak di Jakarta.( Online ) http://sosbud.kompasiana.com/2011/09/29/kasus-bunuh-diri-kembali-marak-di-jakarta di akses 20 Maret 2013

Kultar Singh. (2007). Quantitative Social Research Methods, Singapore:Sage Publications Asia-Pasific

Leadbeater, B. J., Kuperminc, G. P., Hertzog, C., \& Blatt, S. J. (1999). A multivariate model of gender differences in adolescents' internalizing and externalizing disorders. Developmental Psychology, 35, 1268-1282.

Liu, Y., \& Lu, Z. (2011). The Chinese high school student's stress in the school and academic achievement. Educational Psychology: An International Journal of Experimental Educational Psychology, 31(1), 2735 .

MacKinnon, D. P., Lockwood, C. M., Hoffman, J. M., West, S. G., \& Sheets, V. (2002). A comparison of methods to test mediation and other intervening variable effects. Psychological Methods, 7, 83-104.

Payne, M. A. (2012). "all gas and no brakes!": Helpful metaphor or harmful stereotype? Journal of Adolescent Research, 27(1), 3-17.

Santrock, J. (2003). Adolescance : Ninth Edition. New York :McGraw-Hill Companies Inc.

Shahmohammadi. (2011). Students` coping with stress at hight school level particulary at $11^{\text {th }} \& 12^{\text {th }}$ grade. Jurnal social and behavioral sciences. 30, 395-401.

Suara Merdeka. (2011). Peningkatan Angka Bunuh Diri Memprihatinkan . (Online) http://suaramerdeka.com/v1/index.php/read/news/2011/11/27/102888/Peningkatan-Angka-Bunuh-DiriMemprihatinkan di akses 20 Maret 2013) 